\title{
IS THERE A HORMONAL REGULATION OF PHAGOCYTOSIS AT UNICELLULAR AND MULTICELLULAR LEVELS? A CRITICAL REVIEW
}

\author{
GYÖRGY CSABA* \\ Department of Genetics, Cell- and Immunobiology, Semmelweis University, Budapest, \\ Hungary
}

(Received: 7 March 2017; accepted: 10 April 2017)

\begin{abstract}
Phagocytosis is an ancient cell function, which is similar at unicellular and multicellular levels. Unicells synthesize, store, and secrete multicellular (mammalian) hormones, which influence their phagocytosis. Amino acid hormones, such as histamine, serotonin, epinephrine, and melatonin stimulate phagocytosis, whereas peptide hormones, such as adrenocorticotropic hormone (ACTH), insulin, opioids, arginine vasopressin, and atrial natriuretic peptide decreased it, independently on their chemical structure or function in multicellulars. Macrophage phagocytosis of multicellulars is also stimulated by amino acid hormones, such as histamine, epinephrine, melatonin, and thyroid hormones, however, the effect of peptide hormones is not uniform: prolactin, insulin, glucagon, somatostatin, and leptin have positive effects, whereas ACTH, human chorionic gonadotropin, opioids, and ghrelin have negative ones. Steroid hormones, such as estrogen, hydrocortisone, and dexamethasone are stimulating macrophage phagocytosis, whereas progesterone, aldosterone, and testosterone are depressing it. Considering the data and observations there is not a specific phagocytosis hormone, or a hormonal regulation of phagocytosis neither unicellular, nor multicellular level, however, hormones having specific functions in multicellulars also influence phagocytosis at both levels universally (in unicellulars) or individually (in macrophages). Nevertheless, the hormonal influence cannot be neglected, as phagocytosis (as a function) is rather sensitive to minute dose of hormones and endocrine disruptors. The hormonal influence of phagocytosis by macrophages can be deduced to the events at unicellular level.
\end{abstract}

Keywords: phagocytosis, Tetrahymena, macrophage, evolution, hormonal effects

Phagocytosis is a basic life function for unicellulars. Corpuscular elements as nourishments or hostile other unicellulars are engulfed by it. Phagocytosis does not a universal function of all cells in the multicellular world, however, it is

*E-mail: csaba.gyorgy@med.semmelweis-univ.hu 
absolutely needed as a step of innate immunity, which initiates the adaptive immune response. Macrophages, neutrophil granulocytes, and dendritic cells recognize the large particles (at least $0.5 \mu \mathrm{m}$ ) and engulf them by using pseudopods $[1,2]$, which included the phagocytized cell or material. Actin filaments have a role in transporting the phagocytic vesicles, which finished their way after fusing with lysosomes. This is a complex process, which is spontaneously executed, however, it could take or tolerate hormonal regulation.

In multicellular organisms, hormones are at the service of chemical regulation and phagocytic cells are hormonally influenced [3]. Unicellulars synthesize, store, and secrete amino acid- and polypeptide-type hormones characteristic to multicellular animals (mammals) [4-14]. In addition, the cells have mammalian receptor-like structures in the plasma membrane, which bind these hormones and the cells react to them [15-19], as they have signal transducer pathways [20-23]. Many cell functions of the unicellular ciliate Tetrahymena are influenced by the hormones and their effect sometimes seems to be specific [19]. The first encounter with an artificially given hormone causes hormonal imprinting, which provokes a quantitatively altered reaction and this inherited to the progenies up to the thousandth generations [24, 25].

As hormones influence phagocytosis at both phylogenetic levels, it seems worth to study the character of the effect as well as the similarities and differences.

\section{Facts at Unicellular Level}

\section{Amino acid hormones}

Single histamine treatment increased the phagocytic activity of Tetrahymena pyriformis [26]. Chronic histamine treatment was more intense and the intensified activity remained high after some time in histamine-free medium [27]. The action of histamine was dose-dependent. Serotonin also stimulated phagocytosis in Tetrahymena [28] as well, as epinephrine [29]. In Tetrahymena thermophila histamine was ineffective, whereas the antihistamine, diphenhydramine increased it [30]. In other experiments, $\mathrm{H} 1$ and $\mathrm{H} 2$ antagonists were studied and these substances did not influence phagocytosis in T. pyriformis. However, H1 antagonist phenindamine counteracted the phagocytosis stimulating effect of histamine, whereas $\mathrm{H} 2$ antagonist metiamide was ineffective [31]. Serotonin and catecholamine stimulated phagocytosis in T. thermophila [32]. Serotonergic antagonists spiperone and metergoline also stimulated the process, whereas propranolol, alprenolol, and ergocryptine, which are beta and alpha adrenergic antagonists were ineffective or inhibitors [32]. In Paramecium aurelia, beta adrenergic 
agonists (isoproterenol and norepinephrine) enhanced phagocytosis stereospecifically and dose-dependently. The effect was inhibited by propranolol and alprenolol [33]. Histidine, the basic amino acid for histamine formation also stimulated phagocytosis in T. pyriformis even stronger than histamine itself [34].

The pineal hormone, melatonin, between $10^{-6}$ and $10^{-10} \mathrm{M}$ concentrations significantly stimulated the E. coli phagocytosis of $T$. pyriformis $[35,36]$.

The effect of amino acid-type hormones is manifested through the adenylate cyclase-adenosine monophosphate (cAMP) system. Treatment with cAMP or cPDE inhibitors (as theophylline) increases phagocytic activity of $T$. pyriformis $[37,38]$.

\section{Peptide hormones}

Adrenocorticotropic hormone (ACTH) and insulin inhibited the phagocytic activity of Tetrahymena. [39]. In addition, insulin antagonized the phagocytosis increasing action of histamine in $T$. pyriformis [40]. Arginine vasopressin decreased the phagocytic activity of $T$. pyriformis [41]. Atrial natriuretic peptide is also a potent inhibitor of phagocytosis in T. pyriformis [42].

Tetrahymena synthesizes beta-endorphin-like proteins [43] and have receptors for opioid peptides [43], which are suitable for testing opioid peptides of metazoa. These latter inhibit the phagocytotic activity of T. thermophila [44]. Tetrahymena opioids inhibit phagocytosis of Tetrahymena by a naloxonereversible mechanism [45]. The opioid receptors of Tetrahymena are more sensitive to beta-endorphin and most sensitive to morphine [46], which points to the mu-likeness in some pharmacological characters. Chronic treatment with an opioid causes tolerance [47].

\section{Steroid hormones}

Dexamethasone and prednisolone stimulated the phagocytosis by T. pyriformis, but prednisolone-sodium-succinate and deoxycorticosteroneglucoside inhibited it [48].

\section{Facts at Multicellular Level}

\section{Amino acid hormones}

Histamine is believed to be the physiological activator of phagocytosis, since the basic works of Jancsó [49]. These data were supported by the 
experiments with tubercle bacilli [50] and staphylococci [51]. However, there were studies, which demonstrated neutral or negative effects [52]. Epinephrine stimulated macrophage phagocytosis [53], whereas norepinephrine suppressed phagocytosis of wound neutrophils [54].

Induction of phagocytosis in murine macrophages is positively influenced by thyroid hormones through a glutamine mechanism [55]. Exercise (swimming) increases phagocytosis and thyroid hormones are responsible for it [56]. Triiodothyronine (T3) stimulated granulocytes' phagocytic activity [57, 58]. Melatonin increased engulfment of latex beads [59]. Physiological phagocytosis by neutrophil granulocytes seems to be dependent on the presence of nocturnal melatonin surge [60]. Alcohol treatment provokes a drastic decrease in neutrophil phagocytosis, which is restored by melatonin. Stress caused by swimming to exhaustion provoked lower melatonin peak and consequently higher phagocytic activity of macrophages [61]. Melatonin also suppressed phagocytic activity of cultured retinal pigment cells [62].

\section{Peptide hormones}

Prolactin increases the in vitro phagocytic capacity of macrophages [63] and helps to stimulate the exercise (swimming) induced phagocytosis [56]. Folliclestimulating hormone (FSH) negatively influences phagocytic activity of Sertoli cells in tissue cultures [64]. ACTH suppresses phagocytosis of murine peritoneal macrophages [65], however, contradictory results are also known [66]. Chorionic gonadotropin suppresses the phagocytic activity of blood leukocytes and peritoneal macrophages $[67,68]$. Opioids, such as endorphin and dynorphin, stimulate phagocytosis of mouse macrophages [66]. Insulin supports the onset of phagocytosis in inflammatory macrophages by a glutamine-transmitted mechanism [55] and restores neutrophil phagocytosis in diabetic patients [69]. Chronic treatment with insulin strongly depressed the macrophage phagocytosis in rats [70]. The phagocytic activity is low in type 2 diabetes and improves after metabolic improvement [71]. Insulin inhibits phagocytosis of normal human neutrophils [72]. It also enhances immunological phagocytosis by macrophages [72]. Glucagon and somatostatin stimulated macrophage phagocytosis [70]. Met-enkephalin, leu-enkephalin, and beta-endorphin reduced phagocytosis of Candida albicans by human monocytes [73]. Beta-endorphin also suppressed the phagocytic activity of splenic phagocytes and this was antagonized by opioid receptor antagonist, naltrexone [74]. Ghrelin decreased the phagocytic activity of cold-restraint stress exposed rats [75]. Leptin, the adipocyte hormone activates mononuclear phagocytes by a JAK/STAT signaling pathway [76]. 


\section{Steroid hormones}

Estrogen (E2) or progesterone significantly enhanced the phagocytosis of rat peritoneal macrophages [77]. Phagocytosis by human mononuclear cells was stimulated by dexamethasone or hydrocortisone [78]. In tissue culture, murine Sertoli cell phagocytosis was stimulated by hydrocortisone [79]. Prednisolone inhibited the latex phagocytic capacity of human granulocytes, by a receptormediated manner [80]. When prednisolone depressed phagocytic function, vitamin D3 or vitamin E partially restored it [81]. Progesterone reduced E. coli phagocytosis of cultured human decidual cells [82]. Gonadectomy in both sexes (in mice) significantly reduced phagocytic activity of peritoneal macrophages. In females, estradiol supplementation restored the normal condition, however, dihydrotestosterone treatment in males was insufficient [83]. In freshwater snake, Natrix piscator testosterone depressed phagocytic activity of splenic macrophages [84]. In common carp, Cyprinus carpio, beta-estradiol, 11 ketotestosterone, and progesterone suppressed phagocytosis of kidney macrophages in a dosedependent manner $[85,86]$. In tilapia, cortisol and dexamethasone decreased phagocytosis, and aldosterone had a weaker effect [87]. A chronic treatment with estradiol, testosterone, or dihydrotestosterone in chicks significantly depressed the phagocytic activity of macrophages [88].

\section{Conclusions}

Tetrahymena produce amino acid-type hormones as well as peptide ones. However, at unicellular level, there was not systematic investigation of these hormones in case of phagocytosis, but typical hormones were studied which allows the drawing of some conclusions. At multicellular level, more experiments and observation were performed and practically all important mammalian hormones were studied, sometimes with contradictory results, mainly depending on the used methods and subject species. This is understandable, as multicellular phagocytosis is part of the immune process, which have decisive role in the manifestation or healing of human diseases. Nevertheless, although phagocytosis is a rather complex process, mostly the engulfment of neutral particles or bacteria was studied under the effect of hormones and hardly are data on the behavior of actin network, on the encounter and fusion of endocytotic vesicles, etc. However, this has not importance from the aspect of our evaluation as phagocytosis, as a function is studied irrespective of details.

It is indisputable on basis of the data that at both levels of phylogeny hormones can influence phagocytosis. However, it is not known whether it is a 
physiological interaction (regulation), which is needed for the normal execution of the function or coincidental because of the chemical structure of molecules. From evolutionary aspect, the problem seems to be more simple at unicellular level, as all of the amino acid hormones studied positively influenced phagocytosis (Table I), whereas peptide hormones affected it negatively (Table II). As the chemical structures inside the group given are very different and the modified amino acid molecule is easily distinguishable from a peptide chain this could mean that amino acid hormones - or may be amino acids, which were not fully studied from this point of view - are stimulating phagocytosis and polypeptide hormones - or may be peptides, which also have not studied from this point of view - are influencing negatively the process. This is supported by a study, in which histamine and serotonin enhanced the adsorption of fluorescein isothiocyanate (FITC)-labeled bovine serum albumin (BSA) to the plasma membrane of Tetrahymena, while a similar action by insulin was not significant. The degree of BSA binding was similar to the degree of phagocytosis [89]. However, the effect of epinephrine on BSA binding was also not significant which weakens the conclusion.

Steroid hormones positively influenced phagocytosis in $T$. pyriformis (Table III), however, it is questionable whether steroids are used for

Table I. Hormone-influenced phagocytosis in unicellulars: amino acid hormones

\begin{tabular}{lcc}
\hline Hormone & Species & Effect $+/-$ \\
\hline Histamine & TP & + \\
Histamine/chronic & TP & + \\
Serotonin & TP & + \\
Serotonin & TT & 0 \\
Serotonin & TT & + \\
Epinephrine & TT & + \\
Epinephrine & P & + \\
Melatonin & TP & + \\
Histidine (amino acid) & TP & + \\
\hline
\end{tabular}

Note: TP: Tetrahymena pyriformis, TT: Tetrahymena thermophila, P: paramecium.

Table II. Hormone-influenced phagocytosis in unicellulars: peptide hormones

\begin{tabular}{lcc}
\hline Hormone & Species & Effect $+/-$ \\
\hline ACTH & TP & - \\
ANP & TP & - \\
Opioids & TP & - \\
Insulin & TP & - \\
Vasopressin & TP & - \\
\hline
\end{tabular}

Note: TP: Tetrahymena pyriformis. 
Table III. Hormone-influenced phagocytosis in unicellulars: steroid hormones

\begin{tabular}{lcc}
\hline Hormone & Species & Effect $+/-$ \\
\hline Dexamethasone & TP & + \\
Prednisolone & TP & + \\
Prednisolone-sodium-succinate & TP & - \\
Deoxycorticosterone-glucoside & TP & - \\
\hline
\end{tabular}

Note: TP: Tetrahymena pyriformis.

communication at all, as the unicells are living in a watery milieu in which steroids are not dissolved, in addition they have not steroid receptors and their induced steroid receptors are not individual hormone-specific [90].

The ideal phagocyte models in multicellulars are the macrophages as they are the "professional" phagocytes. The effect of amino acid hormones on macrophages is identical with the unicellular ones (Tables IV and VII). However, the effect of peptide hormones is not so clear from this point of view (Table V). At a rough estimate the same amount of them is observed with positive, as negative

Table IV. Hormone-influenced phagocytosis in multicellulars: amino acid hormones

\begin{tabular}{llc}
\hline Hormone & \multicolumn{1}{c}{ Cell type } & Effect $+/-$ \\
\hline Histamine & Macrophage/granulocye & + \\
Epinephrine & Macrophage & + \\
Nor-epinephrine & Macrophage & - \\
Thyroid & Macrophage & + \\
Melatonin & Macrophage & + \\
Melatonin & Retinal pigment & - \\
\hline
\end{tabular}

Table V. Hormone-influenced phagocytosis in multicellulars: peptide hormones

\begin{tabular}{llc}
\hline Hormone & \multicolumn{1}{c}{ Cell type } & Effect + /- \\
\hline Prolactin & Macrophage & + \\
ACTH & Macrophage & - \\
HCG & Macrophage/granulocyte & - \\
FSH & Sertoli cell & - \\
Opioids & Macrophage & + \\
Endorphin & Macrophage & - \\
Insulin & Macrophage & + \\
Insulin/chronic & Macrophage & - \\
Insulin & Granulocyte & - \\
Glucagon & Macrophage & + \\
Somatostatin & Macrophage & + \\
Ghrelin & Macrophage & - \\
Leptin & Macrophage & + \\
\hline
\end{tabular}


Table VI. Hormone-influenced phagocytosis in multicellulars: steroid hormones

\begin{tabular}{llc}
\hline Hormone & \multicolumn{1}{c}{ Cell type } & Effect + - \\
\hline Estrogen & Macrophage & + \\
Estrogen/chronic & Macrophage & - \\
Progesterone & Macrophage & - \\
Progesterone & Macrophage (carp) & - \\
Testosterone & Macrophage & - \\
Ketotestosterone & Macrophage (carp) & - \\
Aldosterone & Macrophage (carp) & - \\
Hydrocortisone & Macrophage & + \\
Hydrocortisone & Sertoli cell & + \\
Dexamethasone & Macrophage & - \\
Prednisolone & Granulocyte & - \\
Testosterone & Splenic macrophage (snake) & + \\
\hline
\end{tabular}

effects. This could mean that in the case of amino acid hormones the amino acid character is dominant, whereas in the case of polypeptide hormones the specificity of the peptide chain. Considering immunity, phagocytosis belongs to the innate immunity, which is absolutely needed for the expression of adaptive immunity, however, this type of phagocytosis is not identical with the unicellulars' phagocytosis, from hormonal aspect. In addition, in multicellulars, the same hormone can participate in the control of innate and adaptive immunity alike [91, 92]. In the case of steroid hormones - and in multicellulars these are working - again their individual character has the decisive role (Table VI). "Glucocorticoids are the main effectors" which are bound by glucocorticoid receptors of immune cells (in macrophages included) [93].

As it was mentioned above, the unicellular Tetrahymena synthesize, store, and secrete hormones characteristic to multicellular animals (mammals). These

Table VII. Comparison of hormone-influenced phagocytosis in unicellulars and multicellulars

\begin{tabular}{lcc}
\hline & Effect in unicellulars & Effect in multicellulars \\
\hline Histamine & + & + \\
Epinephrine & + & + \\
Melatonin & + & + \\
ACTH & - & - \\
Insulin & - & + \\
Opiates & - & Uncertain \\
Dexamethasone & + & + \\
Prednisolone & + & Uncertain \\
\hline
\end{tabular}


unicellular hormones act to cells of metazoa similar to hormones of their own [94]. The unicell also has receptors for mammalian hormones and the receptors' structure is similar to mammalian ones [15, 16, 95], and can transmit hormonal information into the cells, which provokes response. However, the hormones which are classified to a group (e.g. amino acid type or peptide) are provoking similar (identical) reactions (positive by amino acid and negative by peptide). This means that there is not an individual hormone-specificity, but a hormone-type specificity which is not suitable for a hormonal regulation, but enough for being the base of a phylogenetic development of later hormonal control. This makes likely that the regulation by polypeptide hormones and steroids can be deduced to this type of group regulation. It is interesting that in the professional phagocytes (macrophages) of multicellular organisms, the amino acid hormones affect phagocytosis similar to the unicellulars (grouplike), but peptide hormones have individual effect. This could mean that the influence of phagocytosis in the frame of the evolution of immune mechanisms [96] runs parallel with the differentiation of hormones [93] and many components of unicellular phagocytosis have been conserved in higher ranked animals [97].

Phagocytosis is a form of endocytosis, when corpuscular elements are engulfed by the cell and it is a very ancient process [98]. The other form is pinocytosis when dissolved materials are taken up. These materials could be amino acids and these are utilized by the phagocyte for building up proteins. This means that the presence of amino acids in the environment is a positive signal for endocytosis which is also studied by the engulfment of particles (phagocytosis). This could also mean that amino acid hormones stimulate phagocytosis by their amino acid character, and this could explain the uniform effect of them.

The unicellular animal is composed of one cell, however, it is also a complete organism, which has all of the organs (organelles) which are needed for life. It synthesizes all of the water-soluble hormones which have been studied and also can react to them if these materials are present around it in the watery milieu. The macrophages of the multicellular organisms are able to synthesize hormones, however, these are produced by professional hormone producing organs or cells, as there is a division of labor in the organism. Steroid hormones are also produced and transported to the site of the effect. This means that in both cases there is a possibility of hormonal regulation of the phagocytic function [19].

Answering the question in the title of this paper: in our present knowledge, there is not a hormonal regulation of phagocytosis, neither unicellular, nor multicellular level. However, hormones are synthesized, stored, and secreted by unicells which can influence phagocytosis $[99,100]$ and there is a similar situation in multicells, where hormones which has specific functions (e.g., regulation of sugar metabolism, blood calcium level, ovarian cycle, etc.) are also influencing the 
phagocytosis of professional cells (macrophages and neutrophil granulocytes). There is a similar situation if other cell functions would be studied, as specific hormones always have side effects on cells which are not in the mainstream of the hormonal effect. I cannot be excluded the existence of a specific phagocytosis hormone, or hormone-like molecule with specific phagocyte regulating activity at any levels of phylogeny, however, it is not known. At the same time, the hormones presently have been studied permits some evolutionary conclusions: their effects on phagocytosis of macrophages can be deduced to the effects on unicells.

Although in our present knowledge, there is not exist a hormonal regulation of phagocytosis, or specific phagocytosis hormone, the influence of hormones to phagocytosis cannot be undervalued. This is especially very important in our modern world, where hormone-like endocrine disruptors are present in increasing number and increasing amount. There are many data that these materials can alter normal immune functions, phagocytosis included [101-105] and the functional alterations of phagocytosis could cause or promote diseases in the present and future human generations [106-108].

\section{Conflict of Interest}

The author declares no conflict of interest.

\section{References}

1. Flannagan, R. S.: The cell biology of phagocytosis. Annu Rev Pathol 7, 6198 (2012).

2. Aderem, A.: Mechanism of phagocytosis in macrophages. Annu Rev Immunol 17, 593623 (1999).

3. Hunt, I. S., Miller, L., Platt, J. S.: Hormonal regulation of uterine macrophages. Dev Immunol 6, 105-110 (1998).

4. Lajkó, E., Pállinger, É., Csaba, G.: Effect of glucose on the insulin production and insulin binding of Tetrahymena. Acta Microbiol Immunol Hung 59, 461-468 (2012).

5. Rodriguez, E., Lazaro, M. I., Renaud, F. L., Marino, M.: Opioid activity of betaendorphin-like proteins from Tetrahymena. J Eukaryot Microbiol 51, 60-65 (2004).

6. LeRoith, D., Liotta, A. S., Roth, J., Shiloach, J., Lewis, M. E., Pert, C. B., Krieger, D. T.: Corticotropin and beta-endorphin-like materials are native to unicellular organisms. Proc Natl Acad Sci USA 79, 2086-2090 (1982).

7. Berelowitz, M., LeRoith, D., von Schenk, H., Newgard, C., Szabo, M., Frohman, L. A., Shiloach, J., Roth, J.: Somatostatin-like immunoreactivity and biological activity is present in Tetrahymena pyriformis, a ciliated protozoan. Endocrinology 110, 19391944 (1982). 
8. Schwabe, C., LeRoith, D., Thompson, R. P., Shiloach, J., Roth, J.: Relaxin extracted from protozoa (Tetrahymena pyriformis). Molecular and immunological properties. J Biol Chem 258, 2778-2781 (1983).

9. Deftos, L. J., LeRoith, D., Shiloach, J., Roth, J.: Salmon calcitonin-like immunoactivity in extracts of Tetrahymena pyriformis. Horm Metab Res 17, 82-85 (1985).

10. LeRoith, D., Shiloach, J., Heffron, R., Rubinovitz, C., Tanenbaum, R., Roth, J.: Insulinrelated material in microbes: Similarities and differences from mammalian insulins. Can J Biochem Cell Biol 63, 839-849 (1985).

11. de Pablo, F., Lesniak, M. A., Hernandez, E. R., LeRoith, D., Shiloach, J., Roth, J.: Extracts of protozoa contain materials that react specifically in the immunoassay for guinea pig insulin. Horm Metab Res 18, 82-87 (1986).

12. Csaba, G., Pállinger, É.: Thyrotropin (TSH) regulates triiodothyronine (T3) production in the unicellular Tetrahymena. Acta Biol Hung 62, 228-234 (2011).

13. Lajkó, E., Pállinger, É., Csaba, G.: Investigations on the triiodothyronine (T3)-specificity of thyrotropic (TSH) and gonadotropic (HCG) hormone in the unicellular Tetrahymena. Acta Microbiol Immunol Hung 58, 85-91 (2011).

14. Csaba, G., Pállinger, É.: Is there a hormonal network in Tetrahymena? A systematic investigation of hormonal effects on the hormone content. Cell Biochem Funct 26, 303308 (2008).

15. Christopher, G. K., Sundermann, C. A.: Isolation and characterization of the insulin binding sites of Tetrahymena pyriformis. Biochem Biophys Res Commun 212, 515-523 (1995).

16. Christensen, S. T., Guerra, C. F., Awan, A., Wheatley, D. N., Satir, P.: Insulin receptorlike proteins in Tetrahymena thermophila ciliary membranes. Curr Biol 13, R50-R52 (2003).

17. Chiesa, R., Silva, W. I., Renaud, F. L.: Pharmacological characterization of an opioid receptor in the ciliate Tetrtahymena. J Eukaryot Microbiol 40, 800-804 (1993)

18. Csaba, G., Kovács, P.: Oxytocin and vasopressin change the activity of the contractile vacuole in Tetrahymena: Newer contributions to the phylogeny of hormones and hormone receptors. Comp Biochem Physiol Comp Physiol 102, 353-355 (1992).

19. Csaba, G.: The hormonal system of the unicellular Tetrahymena: A review with evolutionary aspects. Acta Microbiol Immunol Hung 59, 131-156 (2012).

20. Shpakov, A. O., Derkach, K. V., Uspenskaia, Z. I.: Effect of natural amino acids and sugars on cyclase activities in infusoria Tetrahymena pyriformis and Dileptus anser. $\mathrm{Zh}$ Evol Biokhim Fiziol 47, 128-135 (2011).

21. Köhidai, L., Barsony, J., Roth, J., Marx, S. J.: Rapid effects of insulin on cyclic GMP location in an intact protozoan. Experientia 15, 476-481 (1992).

22. Shpakov, A. O., Derkach, K. V., Uspenskaya, Z. I.: Glucose and cyclic adenosine monophosphate stimulate activities of adenylate cyclase and guanylate cyclase of Tetrahymena pyriformis infusoria. Bull Exp Biol Med 152, 427-430 (2012).

23. Plattner, H.: Signalling in ciliates: Long-and short-range signals and molecular determinants for cellular dynamics. Biol Rev Camb Philos Soc 92, 60-107 (2017).

24. Csaba, G.: Hormonal imprinting in the unicellular Tetrahymena: The proto-model of epigenetics. Acta Microbiol Immunol Hung 59, 291-310 (2012). 
25. Kőhidai, L., Lajkó, E., Pállinger, É., Csaba, G.: Verification of epigenetic inheritance in a unicellular model system: Multigenerational effects of hormonal imprinting. Cell Biol Int 36, 951-959 (2012).

26. Csaba, G., Nagy, S. U., Lantos, T.: Are biogenic amines acting on Tetrahymena through a cyclic AMP mechanism? Acta Biol Med Ger 35, 259-261 (1976).

27. Csaba, G., Lantos, T.: An attempt to differentiate selection and amplification in hormone receptor development: The unicellular model. Differentiation 8, 57-59 (1977).

28. Darvas, Z., Csaba, G.: Dose-dependent impact of pretreatment (imprinting) with histamine and serotonin on the phagocytic activity of Tetrahymena. Acta Microbiol Hung 37, 285-287 (1990).

29. Csaba, G.: Biogenic amines at a low level of evolution: Production, functions and regulation in the unicellular Tetrahymena. Acta Microbiol Immunol Hung 62, 93-108 (2015).

30. Buduma, N., Balabanian, J., Dalvi, P., Chia, S.-K., Dhaliwal, A, Eliya, D., Boothby, J, Bros-Seemann, S, Kibler, L., Khurt, S., Veregge, S.: Modulation of phagocytosis in Tetrahymena thermophila by histamine and antihistamine diphenhydramine. Acta Protozool 52, 317-323 (2013).

31. Csaba, G., László, V., Darvas, Z.: Effects of H1 and H2 antagonists on Tetrahymena. Acta Biol Med Ger 37, 161-163 (1978).

32. Quinones-Maldonado, V., Renaud, F. L.: Effect of biogenic amines on phagocytosis in Tetrahymena thermophila. J Protozool 34, 435-438 (1987).

33. Wyroba, E.: Beta-adrenergic stimulation of phagocytosis in the unicellular eukaryote Paramecium aurelia. Cell Biol Int Rep 13, 667-678 (1989).

34. Csaba, G., Darvas, Z.: Receptor-level interrelationships of amino acids and the adequate amino acid type hormones in Tetrahymena: A receptor evolution model. Biosystems 19, 55-59 (1986).

35. Kőhidai, L., Vakkuri, O., Keresztesi, M., Pállinger, É., Leppaluoto, J., Csaba, G.: Impact of melatonin on the cell division, phagocytosis and chemotaxis of Tetrahymena pyriformis. Acta Protozool 41, 85-89 (2002).

36. Csaba, G.: Presence in and effects of pineal indoleamines at very low level of phylogeny. Experientia 49, 627-634 (1993).

37. Csaba, G., Nagy, S. U., Lantos, T.: Cyclic AMP and its functional relationship in Tetrahymena: A comparison between phagocytosis and glucose uptake. Acta Biol Med Ger 37, 505-507 (1978).

38. Csaba, G., Lantos, T.: Effect of cyclic AMP and theophylline on phagocytotic activity of Tetrahymena pyriformis. Experientia 32, 321-322 (1976).

39. Kőhidai, L., Lovas, B., Csaba, G.: Effect of adrenocorticotropic hormone (ACTH) and insulin on the phagocytic capacity of Tetrahymena. Zoolog Sci 12, 277-281 (1995).

40. Csaba, G., Darvas, Z.: Insulin antagonizes the phagocytosis stimulating action of histamine in Tetrahymena. Biosci Rep 12, 23-27 (1992).

41. Jahn, I., Csaba, G.: The influence of arginine vasopressin (AVP) on phagocytosis in the unicellular Tetrahymena. Acta Protozool 26, 39-44 (1987).

42. Köhidai, L., Csaba, G., Karsa, J.: Effects of atrial natriuretic peptide on the unicellular Tetrahymena pyriformis model. Microbios 82, 27-40 (1995).

43. Rodriguez, E., Lazaro, M. I., Renaud, F. L., Marino, M.: Opioid activity of beta-endorphinlike proteins from Tetrahymena. J Eukaryot Microbiol 51, 60-65 (2004). 
44. DeJesus, S., Renaud, F. L.: Phagocytosis in Tetrahymena thermophila: Naloxone reversible inhibition by opiates. Comp Biochem Physiol C Comp Pharmacol 92, 139-142 (1989).

45. Renaud, F. L., Colon, I., Lebron, J., Ortiz, N., Rodriguez, F., Cadilla, C.: A novel opioid mechanism seems to modulate phagocytosis in Tetrahymena. J Eukaryot Microbiol 42, 205-207 (1995).

46. Chiesa, R., Silva, W. I., Renaud, F. L.: Pharmacological characterization of an opioid receptor in the ciliate Tetrahymena. J Eukaryot Microbiol 40, 800-804 (1993).

47. Salaman, A., Roman, M., Renaud, F. L., Silva, W. I.: Effect of chronic opioid treatment on phagocytosis in Tetrahymena. Neuropeptides 16, 115-120 (1990).

48. Csaba, G., Lantos, T., Nagy, S. U., Arányi, P., Náray, A.: Effects of steroids on Tetrahymena. Acta Biol Med Ger 37, 1377-1380 (1978).

49. Jancsó, M.: Histamine as a physiological activator of the reticulo-endothelial system. Nature 159, 227 (1947).

50. Gözsy, B., Kató, L.: Studies on the effects of phagocytic stimulation on microbial disease: Stimulation of phagocytic activity of monocytes against tubercle bacilli, strain BCG. Can J Biochem Physiol 34, 571-579 (1956).

51. Northover, J. B.: The effect of histamine and 5-hydroxytryptamine on phagocytosis of staphylococci in vitro by polymorphs and macrophages. J Pathol Bacteriol 82, 355-361 (1961).

52. Azuma, Y., Shinohara, M., Wang, P. L., Hidaka, A., Ohura, K.: Histamine inhibits chemotaxis, phagocytosis, superoxide anion production, and the production of TNF alpha and IL-12 by macrophages via H2-receptors. Int Immunopharmacol 1, 1867-1875 (2001).

53. Zhou, J., Yan, J., Liang, H., Jiang, J.: Epinephrine enhances the response of macrophages under LPS stimulation. Biomed Res Int 2014, Article ID 254686 (2014).

54. Gosain, A., Gamelli, R. L., Di Pietro, L. A.: Norepinephrine mediated suppression of phagocytosis by wound neutrophils. J Surg Res 152, 311-318 (2009).

55. Costa Rosa, L. E., Cury, Y., Curi, R.: Hormonal control of macrophage function and glutamine metabolism. Biochem Cell Biol 69, 309-312 (1991).

56. Ortega, E., Rodriguez, M. J., Barriga, C., Forner, M. A.: Corticosterone, prolactin and thyroid hormones as hormonal mediators of stimulated phagocytic capacity of peritoneal macrophages after high-intensity exercise. Int J Sports Med 17, 149-155 (1996).

57. De Vito, P., Balducci, V., Leone, S., Percario, Z., Mangino, G., Davis, P. J., Davis, F. B., Alfabris, E., Luly, P., Pedersen, J. Z., Incerpi, S.: Nongenomic effects of thyroid hormones on the immune system cells: New targets, old players. Steroids 77, 988-995 (2012).

58. Balázs, C., Leövey, A., Szabó, M., Bakó, G.: Stimulating effect of triiodothyronine on cell-mediated immunity. Eur J Clin Pharmacol 17, 19-23 (1980).

59. Kanchev, I. N., Baichev, J., Kamenov, I., Baikov, B., Hallak, A. K.: Melatonin, corticosterone, stress and phagocytic activity. Bulg J Vet Med 9, 257-264 (2006).

60. Hriscu, M. I.: Modulatory factors of circadian phagocytic activity. Ann N Y Acad Sci 1057, 403-430 (2005).

61. Barriga, C., Martin, M. I., Tabla, R., Ortega, R., Rodriguez, A. B.: Circadian rhythm of melatonin, corticosterone and phagocytosis: Effect of stress. J Pineal Res 30, 180-187 (2001). 
62. Ogino, N., Matsumura, M., Shirakawa, H., Tsukahara, I.: Phagocytic activity of cultured retinal pigment epithelial cells from chick embryo: Inhibition by melatonin and cyclic AMP, and its reversal by taurine and cyclic GMP. Ophtalmic Res 15, 72-89 (1983).

63. Ortega, E., Ferner, M. A., Barriga, C.: Effect of prolactin on the in vitro phagocytic capacity of macrophages. Comp Immunol Microbiol Infect Dis 19, 139-146 (1996).

64. Filippini, A., Russo, M. A., Palombi, F., Bertalot, G., De Cesaris, P., Stefanini, M., Ziparo, E.: Modulation of phagocytic activity in cultured Sertoli cells. Gamete Res 23, 367-375 (1989).

65. Ichinose, M., Savada, M., Maeno, T.: Suppression of phagocytosis by adrenocorticotropic hormone in murine peritoneal macrophages. Regul Pept 54, 457-466 (1994).

66. Xiaojing, W.: The effects of different opiate peptides and ACTH on the phagocytosis of mouse macrophages. Chin J Immunol 4 (1987).

67. Shirshev, S. V., Gorbunova, O. L.: Various mechanisms of the direct and indirect effects of chorionic gonadotropin on the phagocytic activity of leukocytes. Izv Akad Nauk Ser Biol 1, 24-29 (2008).

68. Pernteleva-Rostaing, E., Fontagné, J., Adolphe, M., Engellman, P., Morin, P., Lechat, P.: Effect of human chorionic gonadotropin on phagocytic activity and proliferative capacity of rat peritoneal macrophages in culture. Acta Endocrinol (Copenh) 92, 187-192 (1979).

69. Yano, H., Kinoshita, M., Fujino, K., Nakashima, M., Yamamoto, Y., Miyazaki, H., Mamada, K., Ono, S., Iwaya, K., Saitoh, D., Seki, S., Tanaka, Z.: Insulin treatment directly restores neutrophil phagocytosis and bactericidal activity in diabetic mice and thereby improves surgical site Staphylococcus aureus infection. Infect Immun 80, 4409-4416 (2012).

70. Cornell, R. P., McClellan, C. C.: Modulation of hepatic reticuloendothelial system phagocytosis by pancreatic hormones. J Reticuloendothel Soc 32, 397-407 (1982).

71. Lecube, A., Pechon, G., Petriz, J., Hernandez, C., Simo, R.: Phagocytic activity is impaired in Type 2 diabetes mellitus and increases after metabolic improvement. PLoS One 6, e23366 (2011).

72. Lima, A. O., Queiroz, M., Brascher, H. M., Vargens, J.: Effect of insulin on immunological phagocytosis by macrophages. Experientia 35, 119-120 (1979).

73. Prieto, J., Subira, M. L., Castilla, A., Arroyo, J. L., Serrano, M.: Opioid peptides modulate the organization of vimentin filaments, phagocytic activity, and expression of surface molecules in monocytes. Scand J Immunol 29, 391-398 (1989).

74. Kumar, S., Ghorai, S. M., Rai, U.: Beta-endorphin inhibits phagocytic activity of lizard splenic phagocytes through mu receptor-coupled adenylate cyclase-protein kinase A signaling pathway. Gen Comp Endocrinol 171, 301-308 (2011).

75. Turner, C., Bilgin, H. M., Obay, B. D., Diken, H., Tasdemir, E., Sermet, A.: Effect of ghrelin administration on phagocytic activity in acute cold restrained rats. Regul Pept 138, 113-117 (2007).

76. Shirsev, S. V., Orlova, E. G.: Molecular mechanisms of regulation of functional activity of mononuclear phagocytes by leptin. Biochemistry (Mosc) 70, 841-847 (2005).

77. Chao, T. C., Phuangsab, A., Van Alten, P. J., Walter, R.: Steroid sex hormones and macrophage function: Regulation of chemoluminescence and phagocytosis. Am J Reprod Immunol 35, 106-113 (1996).

78. Kay, J., Czop, J. K.: Enhancement of human monocyte beta-glucan receptors by glucocorticoids. Immunology 81, 96-102 (1994). 
79. Tokuda, N., Mano, T., Levy, R. B.: Phagocytosis by the murine testicular TM4 Sertoli cell line in culture. J Urol 147, 278-282 (1992).

80. Jones, C. J. P., Morris, K. J., Malcolm, I., Jayson, V.: Prednisolone inhibits phagocytosis by polymorphonuclear leucocytes via steroid receptor mediated events. Ann Rheum Dis 42, 56-62 (1983).

81. Shimansky, O., Lisakovska, O. O., Mazanova, A. O., Riasniy, V. M., Veliky, M. M.: Effect of vitamin D3 and vitamin E on prednisolone-induced alterations of phagocyte function. Eur Rev Med Pharmacol Sci 20, 1379-1383 (2016).

82. Ruiz, C., Montes, M. J., Abadia-Molina, A. C., Olivares, E. G.: Phagocytosis by fresh and cultured human decidual stromal cells: Opposite effects of interleukin-1 alpha and progesterone. J Reprod Immunol 33, 15-26 (1997).

83. Baranau, R. I., Tenenbaum, A., Rumi, L. S.: Effects of sexual steroid hormones on the functionality of murine peritoneal macrophages. Steroids 56, 481-485 (1991).

84. Tripathi, M. K., Singh, R.: Differential suppressive effects of testosterone on immune function in fresh water snake, Natrix piscator: An in vitro study. PLoS One 9, e104431 (2014).

85. Yamaguchi, T., Watanuki, H., Sakai, M.: Effects of estradiol, progesterone and testosterone on the function of carp, Cyprinus carpio, phagocytes in vitro. Comp Biochem Physiol C Toxicol Pharmacol 129, 49-55 (2001).

86. Watanuki, H., Yamaguchi, T., Sakai, M.: Suppression in function of phagocytic cells in common carp Cyprinus carpio L. injected with estradiol, progesterone or 11-ketotestosterone. Comp Biochem Physiol C Toxicol Pharmacol 132, 407-413 (2002).

87. Law, W. Y., Chen, W. H., Song, Z. L., Dufour, S., Chang, C. F.: Differential in vitro suppressive effects of steroids on leukocyte phagocytosis in two teleosts, tilapia and common carp. Gen Comp Endocrinol 121, 163-172 (2001).

88. Jutel, M., Blaser, K., Akdis, C. A.: The role of histamine in regulation of immune responses. Chem Immunol Allergy 91, 174-187 (2006).

89. Kovács, P., Csaba, G., Csöregh, É.: Influence of endocytosis-stimulating hormones on the protein binding capacity of the cell membrane. Acta Physiol Hung 61, 213-216 (1983).

90. Csaba, G., Inczefi-Gonda, Á.: Specificity of the dexamethasone-induced steroid receptor in Tetrahymena. Experientia 45, 174-175 (1989).

91. Ferstl, R., Akdis, C. A., O’Mahony, L.: Histamine regulation of innate and adaptive immunity. Front Biosci 17, 40-53 (2012).

92. O'Mahony, L., Akdis, M., Akdis, C. A.: Regulation of the immune response and inflammation by histamine and histamine receptors. J Allergy Clin Immunol 128, 1153-1162 (2011).

93. Webster, J. I., Tonelli, L., Sternberg, E. M.: Neuroendocrine regulation of immunity. Annu Rev Immunol 20, 125-163 (2002).

94. Csaba, G., Gaál, A., Kovács, P., Simon, G., Kőhidai, L.: Prolonged elevation of insulin content in the unicellular Tetrahymena after insulin treatment: Induction of insulin production or storage? Cell Biochem Funct 17, 165-173 (1999).

95. Ferreire de Souza, A. M., Lopez, J. A.: Insulin or insulin-like studies on unicellular organisms: A review. Braz Arch Biol Technol 47, 973-981 (2004).

96. Danilova, N.: The evolution of immune mechanisms. J Exp Zool B Mol Dev Evol 306, 496-520 (2006). 
97. Jacobs, M. E., DeSouza, L. V., Samaranayke, H., Perlman, R. I., Sui, W. M., Klobutcher, L. A.: The Tetrahymena thermophila phagosome proteome. Eukaryote Cell 5, 1990-2000 (2006).

98. Boulais, J., Trost, M., Landry, C. R., Dieckmann, R., Levy, E. D., Soldati, T., Michnick, S. W., Thibault, P., Desjardins, M.: Molecular characterization of the evolution of phagosomes. Mol Syst Biol 6, 423 (2010).

99. Csaba, G.: Hormonal actions in the Protozoan stress. Acta Microbiol Immunol Hung 62, 331-339 (2015).

100. Csaba, G.: Lectins and Tetrahymena - A review. Acta Microbiol Immunol Hung 63, 279-291 (2016).

101. Couleau, N., Falla, J., Beillerot, A., Battaglia, E., D’Innozenzo, M., Plancon, S., Laval-Gilly, P., Bennasroune, A.: Effects of endocrine disruptors on human macrophage-like THP-1 cell response. PLoS One 10, e0131428 (2015).

102. Csaba, G.: Immunoendocrinology: Faulty hormonal imprinting in the immune system. Acta Microbiol Immunol Hung 61, 89-106 (2014).

103. Dunbar, B., Patel, M., Fahey, J., Wira, C.: Endocrine control of mucosal immunity in the female reproductive tract: Impact of environmental disruptors. Mol Cell Endocrinol 354, 85-93 (2012).

104. Liu, P., Wen, W. H., Song, X. X., Yuan, W. H.: [Effects of mixed cypermethrin and methylparathion on endocrine hormone levels and immune functions in rats: I. Doseresponse relationship]. Wei Sheng Yan Jiu 35, 257-260 (2006).

105. Bennasroune, A., Rojas, L., Foucaud, L., Goulaouic, S., Laval-Gilly, P., Fickova, M., Couleau, N., Durandet, C., Henry, S., Falla, J.: Effects of 4-nonylphenol and/or diisononylphtalate on THP-1 cells: Impact of endocrine disruptors on human immune system parameters. Int J Immunopathol Pharmacol 25, 365-376 (2012).

106. Ho, S. M., Cheong, A., Adgent, M. A., Veevers, J., Suen, A. A., Tam, N. N., Leung, Y. K., Jefferson, W. N., Williams, C. J.: Environmental factors, epigenetics, and developmental origin of reproductive diseases. Reprod Toxicol 68, 85-104 (2017).

107. Charles, M. A., Delpierre, C., Bréant, B.: Developmental origin of health and adult diseases (DOHaD): Evolution of concept over three decades. Med Sci (Paris) 32, 15-20 (2016).

108. Csaba, G.: The biological basis and clinical significance of hormonal imprinting, an epigenetic process. Clin Epigenetics 2, 187-196 (2011). 